\title{
IMPACTS OF BANKING DEREGULATION ON RURAL CAPITAL MARKETS: EVIDENCE FROM VIRGINIA AND TENNESSEE
}

\author{
Deborah Morentz Markley*
}

\section{Introduction}

The 1980s have brought major changes to the United States banking system. The Depository Institutions Deregulation and Monetary Control Act (DIDMCA), passed in 1980 , is regarded as the most significant regulatory package affecting financial institutions since the banking regulations passed following the Depression. At the same time, there have been important changes taking place in various regions that are altering the extent and character of interstate finance in this country. While interstate banking officially has not been sanctioned by Congress, there is no question that the stage is set for full-scale interstate banking in the next few years.

With these major changes occurring at the national level, it is important to consider what impact, if any, these macroeconomic changes will have on rural areas of the country. Rural financial markets typically have been isolated from national market changes, primarily due to the regulations applied to commercial banks and thrift institutions in the past. These regulations created truly local banking markets by restricting the geographical reach of large, metropolitan bank competitors and by establishing a ceiling on deposit interest rates, thus protecting the small bank's profitability. With the elimination of this protection in the 1980 s, major changes are expected to occur in rural capital markets.

Deregulation is expected to result in an increase in bank mergers and an increase in the number of banking institutions affiliated through multibank holding companies. This movement represents the continuation of a trend, evident since the 1970s, of increasing importance of bank holding companies in the national financial market (Savage). Some research suggests that the presence of large bank holding companies may have a beneficial effect on rural capital markets. Evidence from Wisconsin shows that small rural banks lack the skills and experience required to put together complex and innovative financial

\footnotetext{
*The author is currently Adjunct Professor, Department of Agricultural and Resource Economics, University of Massachusetts, Amherst. This paper was prepared while the author was Assistant Professor, Department of Agricultural Economics and Rural Sociology, University of Tennessee, Knoxville. An earlier version of this paper was presented at the Southern Regional Science Association Annual Meetings, New Orleans, 1986. The author gratefully wishes to acknowledge the helpful comments of Dr. Emil Malizia and three anonymous reviewers.
}

packages that might benefit local businesses (Taff, Pulver, and Staniforth). If these constraints exist for most rural banks, the presence of larger institutions in a deregulated rural financial market may increase the capital available to the business sector.

Other research suggests that the impact of deregulation will vary among different rural areas. Work by Barkley, Potts, and Mellon in Arizona and Colorado suggests that under a branch banking, as opposed to a unit banking system, there is an intrarural transfer of loanable funds from more slowly growing to more rapidly growing rural areas. These results suggest that deregulation will not lead to an outflow of funds from all rural to urban areas, but that some more depressed rural areas may have reduced capital availability. However, it remains to be determined whether reduced capital availability in these areas actually results in a shortage of capital relative to demand.

Mikesell suggests that, in spite of lower loan to deposit ratios, small rural banks provide a level of support for local borrowers similar to that found in larger, urban institutions. The lower level of lending likely results from inadequate demand and the lack of profitable lending opportunities in depressed rural areas, rather than from conservative behavior on the part of rural bankers. If this result is substantiated, there will less likely be a positive impact on rural areas as a result of deregulation, since large bank holding companies are unlikely to create lending opportunities where none exist.

However, a study by Dunham yielded conflicting results. Small banks were found to return a smaller percent of their locally generated deposits in loans to the community than did large money center banks. Comparing local sources to local uses of funds for each type of bank, Dunham found that $\mathbf{4 0}$ percent of a small bank's locally generated deposits were placed in nonlocal investment. For large banks, parity was achieved in local sources and uses of funds. These results suggest that larger banks may not drain rural areas of funds.

\section{Problem Statement}

Deregulation was designed to increase the level of efficiency in the national capital market without specific consideration of the consequences for local markets. If financial deregulation is expected to result in a greater number of banks affiliated with multibank holding companies and fewer independent banks, it is important to 
identify the potential impact of this changing bank organizational structure for rural capital markets. Rural capital markets have traditionally been characterized by local independent banks. An increase in bank mergers and the consequent rise in the number of holding company banks serving rural markets represents an important source of institutional change for rural areas. However, there is limited understanding of whether differences in bank organizational structure, i.e., independent versus affiliate bank, translate into performance differences in the local capital market. As a result, the studies conducted in Virginia and Tennessee were designed to identify the impact of changing bank organizational structure on the way decisions are made in one type of institution versus the other and the resulting pattern of capital availability for particular sectors in the rural economy.

\section{Research Objectives and Hypotheses}

An objective in both studies was to examine the potential impact of financial deregulation on capital availability in nonmetropolitan areas by investigating whether bank decision-making behavior and operating performance varied by the organizational structure of the bank. In particular, the Virginia study focused on how bank organizational structure, i.e., independent bank versus affiliate of a multibank holding company, affected bank decision-making. The primary objective was to evaluate how decisions were made in each type of bank, the differences that existed, and how these differences were reflected in bank performance. The Tennessee study, on the other hand, focused primarily on the relationship between organizational structure and bank operating performance. The primary objective was to evaluate how bank structure affected performance in terms of lending behavior, profitability, and capitalization.

In the Virginia study, it was hypothesized that affiliate and independent banks behave differently. This hypothesis was tested by determining differences in operating goals of the two types of bankers using the lexicographic ordering procedure. The lexicographic ordering method was used since it represents decision-making as a process in which multiple goals are considered. In addition, performance was expected to vary by bank type. This hypothesis was tested by using discriminant analysis on a number of key bank operating statistics, e.g., return on assets, loans/deposits, loan losses. In the Tennessee study, it was again hypothesized that the performance of affiliate and independent banks was different. This hypothesis was tested using the step-wise discriminant analysis employed in the Virginia study and some of the same independent variables to measure bank operating performance.
In both studies, a rural capital market was defined as the commercial banking institutions operating within nonmetropolitan counties in each state. While it is recognized that a financial market contains more institutions than commercial banks, to simplify the analysis and make it manageable, only commercial banks were included in the financial markets analyzed in these studies. Evidence from Virginia and Tennessee suggests that no single type of banking institution is appropriate for all rural areas. There are advantages and disadvantages to an independent banking structure as well as to a bank holding company structure. These results and their implications for rural capital availability are discussed in the next section.

\section{Results}

\section{Evidence from Virginia}

The work in Virginia combined a case study analysis of independent versus affiliate bank decision-making with an aggregate step-wise discriminant analysis of relative bank performance. The case study approach paired an independent bank with an affiliate bank in four different nonmetropolitan areas. ${ }^{1}$ The primary objective of the case study was to determine whether or not affiliate and independent bankers had similar decision-making behavior. The case study was designed to control for differences in size and the economic structure of the local area by pairing banks of similar asset size operating in the same nonmetropolitan county. ${ }^{2}$ By controlling for size and economic structure, any differences in behavior between banks could be more readily attributed to differences in their organizational structure. The aggregate discriminant analysis was conducted to provide support for the more limited case study by determining which bank performance variables were most important in distinguishing nonmetropolitan independent banks from affiliate banks.

\section{Case Study Results}

For the case study analysis, interviews were conducted with the president of each institution to determine whether the bankers were profit maximizers or whether they sought to maximize a number of operating goals, whether decisions were made at the local level or by outside sources, and how much flexibility the bank president had in making key operating decisions. Each banker completed a lexicographic ordering of the operating goals important to overall bank decision-making (Anderson, Dillon, and Hardaker). This technique assumes that bankers consider a number of goals in decision-making, rather than strictly profit. The lexicographic ordering 
technique was selected based on results of a pretest pairing this analysis with the modified Von Neumann-Morgenstern technique, which assumes a single objective preference structure. Bankers indicated that the former technique more accurately reflected their decision-making process. The ordering process used in this study generated for each banker a preference structure, which was then translated into a constrained maximization problem using linear programming to determine whether the banker maximized a single goal, such as profit, or multiple goals. (For a more detailed discussion of the application of this technique and its limitations, see Markley.) Five goals were ranked in order of importance by each banker:

1. Earn a reasonable return on assets.

2. Stimulate community growth.

3. Insure safety of depositors' money.

4. Maintain a satisfactory market share of deposits.

5. Place a satisfactory proportion of loans within service area.

The first, third and fourth goals were included to represent several important aspects of business behavior-profitability, risk attitude, and market share. The second and fifth goals were included to determine the importance bankers attach to stimulating local economic growth.

In order to translate each banker's goal-ordering into a constrained maximization problem, satisfactory levels of achievement for each goal were identified. For example, a banker would determine the minimum return on assets that would be acceptable given the bank's particular circumstances. Only three of the five operating goals were expressed in quantitative terms suitable for a linear programming model-return on assets, market share, and satisfactory loan to deposit ratio. Hence, only these goals were included in the linear programming model developed for each banker.

In addition to the satisfactory levels of achievement for each goal, certain constraints on operating behavior were identified by the bankers and incorporated into the models. Five types of constraints were used in the models, with specific values determined by each banker.

1. Desired allocation of total loans among specific types in the portfolio-real estate, commercial and industrial, agricultural, and consumer/installment loans;

2. Maximum value for the loan to deposit ratio;

3. Percent of total deposits allocated to cash, municipal bonds, and/or United States treasuries;

4. Total 1982 real estate loans greater than or equal to 95 percent of 1981 total real estate loans; and

\section{Total cash greater than or equal to reserves.}

For each banker, the lowest ranked goal was maximized, subject to achieving the satisfactory level set for the other more important goals and to meeting the additional constraints imposed. For most bankers in the analysis, the basic model maximized market share, subject to a maximum loan to deposit ratio and a minimum return on assets. The feasible solution for each model was then compared to the actual bank portfolio to determine how well the lexicographic ordering technique described actual bank behavior.

Table 1 presents the feasible solution values generated through the lexicographic ordering analysis and the actual values for selected bank operating ratios for each type of bank in the four rural areas. These results suggest that most of the independent and affiliate bankers studied behaved similarly in terms of overall lending and profit performance and could be described as maximizing a multiattribute utility or preference structure, where profit maximization was one of a number of goals or attributes in the banker's preference structure. ${ }^{3}$ Several observations can be made based on these results. First, the relatively large differences between predicted and actual values resulted from an inability of the model to precisely describe bank decision-making. In many cases, predicted values were set at the maximum possible, based on model constraints which did not always accurately represent market realities. However, since relative values were the focus of attention in this study, these differences did not bias the results.

Second, in counties 2 and 3, differences in independent and affiliate bank lending behavior described by the model did not translate intodifferences in the performance of the two banks when actual portfolio data were compared. This result suggests that local economic conditions and the competitive environment in these counties may be more important than institutional structure in constraining either the decision-making or the performance of the banks.

Third, results from the lexicographic ordering analysis and the comparison of actual portfolios for the two banks in the coal region of Virginia, a relatively undiversified rural economy, showed that the affiliate banker behaved less conservatively than the independent banker considering both predicted and actual loan to deposit ratios. The affiliate banker who was interviewed had a much higher loan to deposit ratio than did the independent banker; that is, the affiliate bank had 70 percent of its deposits in loans while the independent bank had only 33 percent of its deposits in loans. The explanation for this less conservative behavior would appear to lie in the more diversified structure of the holding company. 
Table 1

Comparison of Ratio Values Predicted from Feasible Solution with Actual Portfolio Values for Independent and Affiliate Banks in Four Nonmetropolitan Areas of Virginia

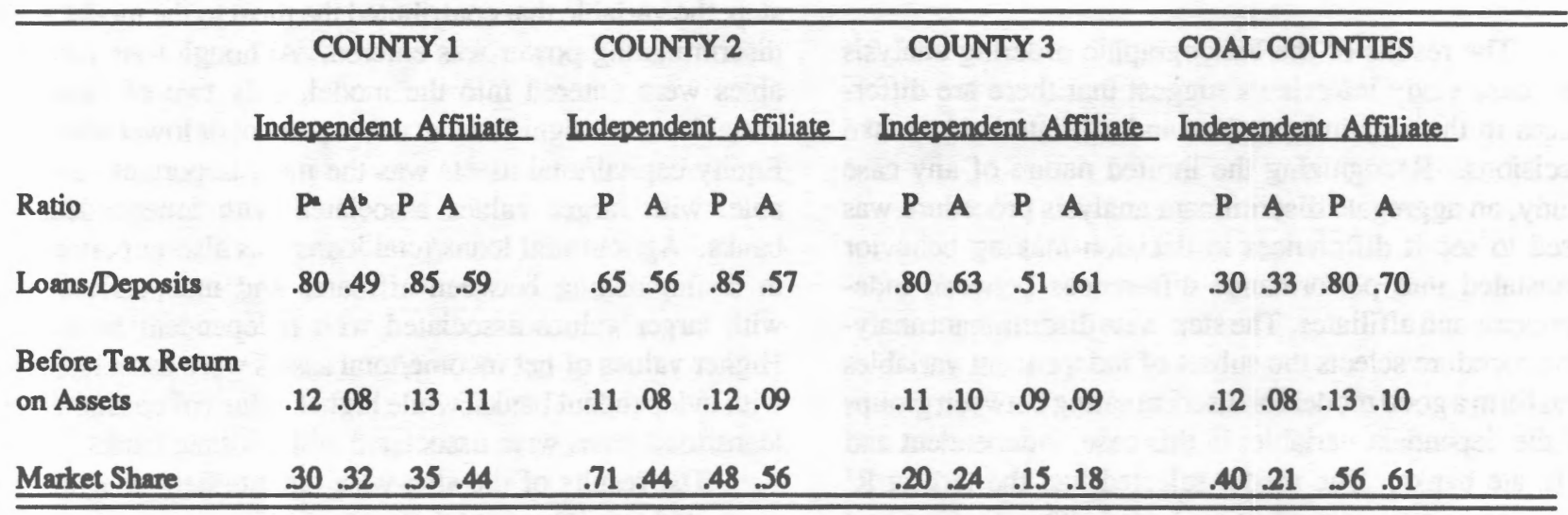

a Predicted values from feasible solution

b Actual values from bank portfolio

Through the holding company structure, affiliate banks have a ready market in other affiliated institutions for their loans. Because of this relationship, the affiliate banker could place a higher percentage of the bank's deposits into loans made to the coal industry with less concern about the consequences of an economic decline. In the event of unfavorable economic conditions in the coal industry, these loans could be sold off to institutions within the holding company located in other parts of the state, helping to ensure a degree of diversification that an independent bank does not enjoy. An independent banker has little choice in an economy like the coal region, except to behave conservatively and maintain a relatively low level of loan exposure in that single industry. In the other more economically diversified counties surveyed in the case study, there was no difference between the behavior of independents and affiliates in terms of loan to deposit ratios.

Although the lexicographic ordering analysis showed few differences between the decision-making behavior of independent and affiliate bankers, other information obtained in the case study interviews highlighted two important differences. First, while both independent and affiliate bankers appeared to maximize multiple goals such as maintaining a satisfactory market share and loan to deposit ratio, and earning an acceptable rate of profit or return on their assets, the locus of decision-making authority was quite different. The independent bankers made their operating decisions at the local level, in response to local conditions. As a consequence, the inde- pendent bankers had greater operating flexibility relative to the affiliate bankers.

Affiliate bankers, on the other hand, typically received operating guidelines for use in policy-making from holding company headquarters. They were constrained by policy guidelines (1) typically established in a metropolitan area removed from local conditions and (2) designed to be applied by all of the affiliates in the holding company network regardless of their particular local circumstances. The affiliate bankers who were interviewed expressed concern that these universal guidelines constrained their ability to compete and to respond to local conditions. The greater operating flexibility for local independent banks may be an important factor in their ability to compete with large bank holding companies, such as in California and New York state. This result also supports a continued role for independent bankers in the national financial system as providers of retail or community banking services.

Second, the affiliate bankers who were interviewed were able to offer their local communities a more complete range of financial services than were the independent bankers. The independent bankers suggested that the affiliate bank's access to the larger staff and greater range of financial expertise at the holding company level permitted them to offer customers more specialized and complete financial services. This result is supported by the general view that the range of financial services available in a deregulated financial market should be greater than before. It would appear that as the organizational structure 
of a rural financial market shifts toward the holding company form of bank, the range of financial services available to consumers and local businesses improves.

\section{Discriminant Analysis Results}

The results of the lexicographic ordering analysis and case study interviews suggest that there are differences in the way independent and affiliate banks make decisions. Recognizing the limited nature of any case study, an aggregate discriminant analysis procedure was used to see if differences in decision-making behavior translated into performance differences between independents and affiliates. The step-wise discriminant analysis procedure selects the subset of independent variables that form a good model for discriminating between groups of the dependent variable, in this case, independent and affiliate banks. The model selected had the largest $\mathbf{R}^{\mathbf{2}}$ value among those models evaluated. This analysis was run using Federal Reserve data for 123 banks operating in Virginia in 1982. Nine independent variables were included in the analysis:

1. Total loans/deposits;

2. Consumer loans/total loans;

3. Agricultural loans/total loans;

4. Commercial and industrial loans/total loans;

5. Equity capital/total assets;

6. Net income/total assets;
7. Loan losses after recoveries/total loans;

8. County population in 1980; and

9. County average per capita income in 1981.

Table 2 presents the results of this analysis. At each step, the variable that contributed the most to the model's discriminating power was entered. Although four variables were entered into the model, only two of those variables were significant at a five percent or lower level. Equity capital/total assets was the most important variable, with larger values associated with independent banks. Agricultural loans/total loans was also important in distinguishing between affiliates and independents, with larger values associated with independent banks. Higher values of net income/total assets were associated with independent banks, while higher values of consumer loans/total loans were associated with affiliate banks.

The results of the step-wise discriminant analysis suggested two important differences between nonmetropolitan independent and affiliate banks in terms of their operating performance or support for different sectors of the local economy. First, the higher ratio of equity capital to total assets for independents than for affiliates results from the fact that capital tends to be retained at the holding company level and allocated among affiliates as needed. As such, this difference results from the more centralized structure of the holding company, rather than from a basic difference in decision-making at the individual bank level.

Table 2

Results of Step-Wise Discriminant Analysis in Virginia: Rank of Variable by Power to Discriminate between Nonmetropolitan Independent and Affiliate Banks, 1982

$(n=123)$

\begin{tabular}{lccc}
\multicolumn{1}{c}{ Variable } & Step Entered & F Statistic & Prob $>$ F \\
\hline $\begin{array}{l}\text { Equity capital/ } \\
\text { Total assets }\end{array}$ & 1 & 13.621 & .0003 \\
$\begin{array}{l}\text { Agricultural loans/ } \\
\text { Total loans }\end{array}$ & 2 & 6.065 & \\
$\begin{array}{l}\text { Consumer loans/ } \\
\text { Total loans }\end{array}$ & 3 & 3.015 & .0147 \\
$\begin{array}{l}\text { Net income/ } \\
\text { Total assets }\end{array}$ & 4 & & .0841 \\
\hline \hline
\end{tabular}


Table 3

Summary of Differences in Independent and Affiliate Bank Behavior and Performance:

Virginia Case Study and Discriminant Analysis

1. Both independent and affiliate banks maximize multiple goals, not strictly profit.

2. Independent banks have greater operating flexibility due to local nature of decision-making.

3. Affiliate banks potentially can offer a wider range of financial services to the community.

4. Equity capital/total assets and agricultural loans/total loans are the most important variables distinguishing between independent and affiliate banks in discriminant analysis.

A second and more important difference from a performance standpoint was the higher ratio of agricultural loans to total loans for nonmetropolitan independent banks than for affiliate banks. This result suggests that independent banks provide greater relative support for the agricultural sector than do affiliate banks. The case study results support this conclusion since most of the affiliate banks indicated that the holding company did not have a well-formulated policy to guide agricultural lending decisions and that policies that did exist were often inconsistent with the seasonal credit needs of the farmers. This result suggests a continued role for independent banks in meeting the capital needs of the agricultural sector. This role may become increasingly important given the financial stress apparent in agriculture today and the troubled condition of the Farm Credit Service, designed specifically to meet the credit needs of the nation's farmers.

Table 3 summarizes the evidence from the Virginia study suggesting important differences between independent and affiliate bankers. In some cases, the affiliate bank may bring increased capital and services to rural communities, especially in rural areas lacking economic diversification. However, independent banks have an important role to play in meeting the needs of the agricultural sector, as well as being able to respond to local conditions and potentially to adjust bank policies accordingly.

\section{Evidence from Tennessee}

Drawing on the results from Virginia, this study was designed to identify any differences in the operating performance of independent and affiliate banks in Tennessee. An aggregate analysis of bank operating performance was conducted using the same step-wise discriminant analysis as employed in the Virginia study. This analysis determined the most important variables distin- guishing between independent and affiliate bank performance in nonmetropolitan areas of the state. Data were obtained from the Federal Reserve for 223 nonmetropolitan banks operating in 1982 . Seven bank operating ratios were used as independent variables in this analysis:

1. Total loans/deposits;

2. Agricultural loans/total loans;

3. Consumer loans/total loans;

4. Commercial and industrial loans/total loans;

5. Real estate loans/total loans;

6. Net income/assets; and

7. Equity capital/assets.

Some of the variables used in the Virginia study were eliminated from the Tennessee study since they were deemed to be less important than those described above. In particular, the economic condition variables (population and per capita income) and the loan loss ratio were excluded from the analysis. However, the real estate loans/total loans ratio was included to give a more complete view of the lending portfolio of the bank. This analysis was done to provide an aggregate view of the performance differences between independents and affiliates, and the banks were not paired to control for size or economic structure, as was done in the Virginia case studies. In spite of these differences, results of the research in Tennessee support the results from Virginia in two ways.

First, only two variables were significant in distinguishing between affiliate and independent bank performance (Table 4). The most important variable was the loan to deposit ratio. Affiliate banks had a higher ratio, indicating that a greater proportion of their deposits was used to support lending activities. This result is in line with the notion that affiliate banks behave less conservatively than independent banks, even when economic di- 
versification is not an issue. However, it is important to note that the relatively greater lending activity by affiliate banks indicates only a potential for these banks to provide greater capital to rural areas. The loan to deposit ratio is a rough measure of capital availability since the loans are not distinguished by location; that is, it is not possible to determine how much capital flows into the economy via loans to local residents and businesses and how much flows out of the local economy via loans to other communities or outside businesses.

Second, the other important variable distinguishing between affiliate and independent bank performance was the ratio of agricultural loans to total loans. The indepen- dent banks had a higher ratio relative to affiliates, indicating greater relative support for the agricultural sector. Whether this greater relative support translates into greater capital availability for agriculture is related to the issue described above. It is important to determine whether affiliate banks, by maintaining higher loan to deposit ratios, contribute to increased capital availability in rural communities. If so, their smaller relative support for agriculture may be offset by greater absolute support as capital availability is increased.

In general, these results support the conclusions reached in the Virginia study. Independent and affiliate banks in Tennessee do perform differently, with affiliates

Table 4

Results of Step-Wise Discriminant Analysis in Tennessee: Rank of Variables by Power to Discriminate between Nonmetropolitan Independent and Affiliate Banks, 1982

$(n=223)$

\begin{tabular}{lccc} 
Variable & Step Entered & F Statistic & Prob $>$ F \\
\hline $\begin{array}{l}\text { Loans/Deposits } \\
\begin{array}{l}\text { Agricultural } \\
\text { Loans/Total Loans }\end{array}\end{array}$ & 1 & 11.272 & .0009 \\
\hline \hline
\end{tabular}

potentially providing greater support for overall lending, while independents provide greater relative support for the agricultural sector. As deregulation continues, specifically geographical deregulation, it becomes increasingly important to determine accurately the role of these different institutions in rural capital markets and their impact on capital availability in both absolute and relative terms.

\section{Limitations of Study}

While the results of the studies in Virginia and Tennessee suggest that bank organizational structure affects both bank decision-making and performance, several limitations of these studies should be discussed. First, using the loan to deposit ratio as a measure of relative capital availability from affiliate versus independent institutions has some serious limitations. The potential for increasing capital availability by maintaining a higher loan to deposit ratio may not be realized by an affiliate bank that exports funds from the local market. The loan to deposit ratio reflects total lending performance of the bank, not strictly local lending. As such, this measure is less useful for determining the extent to which an independent or an affiliate bank provides capital to meet local capital needs in a rural community.

Second, the aggregate discriminant analysis in both states is limited to the extent that bank size and the economic structure of the local area are not held constant. Differences in bank performance relative to the agricultural sector, in particular, may be due to differences in the size of independents relative to affiliates or due to a predominance of independent banks in agricultural areas. Although the results of the Virginia case study analysis suggest that bank organizational structure does influence bank decision-making, further work should be done to determine differences using a larger number of banking institutions so that the results have wider applicability. However, such an analysis must be designed to control for factors like bank asset size and the economic structure within which the banks operate.

Third, the limitations of any case study analysis apply to the Virginia study. However, differences in bank behavior were identified through the personal interviews 
that were not identified by using the more aggregate discriminant analysis procedure. The case study approach has merit in evaluating differences in the decision-making of independent and affiliate banks by allowing a more indepth analysis of management behavior in each type of institution. This research approach deserves greater attention in the future.

\section{Conclusions and Issues for Future Research}

The deregulatory changes set in motion with the DIDMCA in 1980 and continuing with trends toward increased geographical expansion of banking institutions are resulting in major structural and institutional changes in the financial markets of this country. The result is likely to be a national financial market characterized by greater competition, greater concentration of financial resources, greater service availability in most local markets, and continued merger activity, with more banks affiliated within holding companies and fewer independents. While deregulation and its relationship to the structure of the overall financial system have been explored widely, the impact on rural capital markets is much less clear.

Research findings from Virginia and Tennessee suggest several potential impacts on rural capital markets as a result of deregulation, but there is no evidence of a single, uniform impact that can be generalized to most rural areas. Evidence from Virginia suggests that a bank market structure with more affiliate and fewer independent banks may mean an increase in the range of services available in rural capital markets and the potential for increased capital availability. However, comparison of the results from the Virginia coal region case study with other results suggests that no single type of banking institution is most appropriate for all rural areas, diversified as well as single industry areas. Based on this result, an argument can be made for ensuring some diversity in the structure of financial markets, particularly at the rural level. Finally, the evidence from both Tennessee and Virginia strongly suggests that support for the agricultural sector will continue to come from rural, independent banks as opposed to urban-based banks and holding companies.

Given these results and the fact that many issues related to the impact of deregulation on rural capital markets remain to be determined, several areas for future research should be stressed. First, given the level of integration of local into national capital markets, research should be designed to determine what constitutes a rural capital market. In this regard, the institutions, both formal and informal, that are important in meeting the demand for capital in rural areas must be identified. Efforts should also be directed at refining measures of rural capital supply and identifying the sources of demand for capital in rural areas. This information can be used to identify how accurately the flow of funds from rural to urban areas or between rural areas reflects available investment opportunities.

Second, both the Virginia and Tennessee analyses treat rural areas as basically homogeneous, although there is some distinction made among rural areas based on the degree of diversification in the local economy. Future analysis of rural banking markets would be improved by recognizing the diversity that exists among rural areas of different sizes and different degrees of rurality or urbanization. This diversity could be introduced by classifying rural areas according to their size and degree of metropolitan influence, e.g., strictly rural, lesser urban, adjacent to SMSA. Rural areas could also be classified according to some measure of economic growth so that rapidly growing areas could be distinguished from slowly growing or declining areas. Within each of these classifications, then, the local banking market could be analyzed to determine any differences in the behavior of affiliates versus independents.

Third, given the increasing number of bank failures, in general, and rural bank failures, in particular, it is important to determine to what extent concentration in local, rural financial markets will increase as a result of deregulation and other macroeconomic changes affecting both rural areas and the financial institutions that serve them. Deregulation has the potential to bring new sources of capital into rural areas and expand service availability. However, if deregulated rural capital markets become increasingly concentrated as a by-product of increased market concentration at the national level, the potential gain in services might be reduced by anticompetitive activities of the remaining institutions.

Fourth, while further research should be directed at clarifying the impact of financial deregulation on rural capital markets, deregulation is but one macroeconomic change that has potential impacts on rural areas. Greater research effort should be devoted toward identifying how macroeconomic changes, whether originating at the national or international level, filter down to and impact on rural parts of this country. For the southern region of the country, the impacts of domestic monetary policies, as they relate to the value of the dollar, have a direct impact on rural export manufacturing industries as well as agriculture. Trends toward increased foreign direct investment in the United States, and particularly in the South, have implications for the type of economic activity and change that will occur in the future. These are just two examples of other types of macroeconomic change that deserve research attention by professionals interested in economic development and change in rural areas of this country.

Economists, regional planners, and other profes- 
sionals involved in the analysis and design of policy should place increased emphasis on how macroeconomic policies affect rural regions of this country. Without a better understanding of the direct and indirect impacts of these policies on rural communities, the ability of rural residents to actively participate in the policy making process to their own benefit is severely limited. When this interaction is limited, the ability of rural communities to adapt to and benefit from such macroeconomic changes is questionable.

\section{NOTES}

${ }^{1}$ An affiliate bank is one that is affiliated with a multibank holding company operating throughout the state or a particular region within the state. An independent bank is one with no outside affiliation, consisting of a single bank that may operate branches within its community. Nonmetropolitan areas were defined as counties lying outside the Standard Metropolitan Statistical Areas defined by the Bureau of the Budget.

${ }^{2}$ Banks from the coal region in Virginia were drawn from two counties since participation by banks of similar size in the same county was not achieved. However, given the similar economic structure in these counties, no bias occurred.

In order to test this result, linear programming models were developed for each banker with strict profit maximization as the objective function. In all cases, these models performed no better or worse than the lexicographic ordering technique in describing each banker's decision-making behavior.

\section{REFERENCES}

Anderson, Jock R., John L. Dillon, and Brian Hardaker. Agricultural Decision Analysis. Ames, Iowa: Iowa State University Press, 1977.

Barkley, David L., Glenn T. Potts, and Cindy Mellon. Bank Structure and Performance at the Nonmetropolitan Level: The Arizona and Colorado Experience. Technical Bulletin Number 251. Agricultural Experiment Station. The University of Arizona, 1984.

Dunham, Constance R. "Interstate Banking and the Outflow of Local Funds." New England Economic Review. (March/April, 1986). 7-19.

Markley, Deborah M. "The Impact of Financial Deregulation on Rural Capital Markets in Virginia: An Analysis of Bank Decision Making." Unpublished Ph.D. Dissertation. Department of Agricultural Economics. Virginia Polytechnic Institute and State University, 1984.

Mikesell, James J. "Rural Banks Reflect the Local Economy." Rural Development Perspectives. Washington, D.C.: ERS, United States Department of Agriculture, 1985.

Savage, Donald T. "Developments in Banking Structure, 1970-81." Federal Reserve Bulletin. Board of Governors of the Federal Reserve System, 1982. 77. 85.

Taff, Steven J., Glen C. Pulver, and Sydney D. Staniforth. Are Small Community Banks Prepared to Make Complex Business Loans? Research Bulletin No. R3263. University of Wisconsin-Madison, 1984. 